\title{
Important role of the nucleotide excision repair pathway in Mycobacterium smegmatis in conferring protection against commonly encountered DNA- damaging agents
}

\author{
Correspondence \\ Umesh Varshney \\ varshney@mcbl.iisc.ernet.in \\ or \\ uvarshney@gmail.com
}

Received 15 April 2008

Revised 13 May 2008

Accepted 22 May 2008

\author{
Krishna Kurthkoti, Pradeep Kumar, Ruchi Jain and Umesh Varshney
}

Department of Microbiology and Cell Biology, Indian Institute of Science, Bangalore 560012, India

\section{INTRODUCTION}

As a part of the host's innate immune response launched to kill microbes, macrophages generate reactive oxygen species (ROS) and reactive nitrogen intermediates (RNI), and foster an environment that is low in $\mathrm{pH}$. The oxyradicals and nitric oxide are highly soluble in lipids and diffuse through the microbial cell wall to cause lethal damage to DNA (Lancaster, 1997). Nitric oxide deaminates cytosine to uracil, adenine to hypoxanthine, and guanine to xanthine (Wink et al., 1991). Oxidative stress results in formation of abasic sites, single- and double-stranded breaks in DNA and damage to nitrogenous bases such as the conversion of guanine to 7,8-dihydro-8-oxoguanine (8oxoG). In addition, reaction of nitric oxide with molecular oxygen or superoxide anion forming peroxynitrite may induce inter-strand $\mathrm{G}-\mathrm{G}$ cross-links and also polyamine DNA cross-links (Hartman et al., 1986; Shapiro et al., 1977). Failure to repair DNA damage is both cytotoxic and mutagenic. Thus DNA lesions are often subject to overlapping repair processes (Cooke et al., 2003).

Mycobacterium tuberculosis, which resides in the host macrophages, is one of the most successful pathogens. It not only tolerates the hostile environment within macrophages but also survives environmental stresses like exposure to UV,

Abbreviations: BER, base excision repair; NER, nucleotide excision repair; RNI, reactive nitrogen intermediates; ROS, reactive oxygen species. dehydration and low temperature during host exchanges (Manganelli et al., 2004). Although the DNA damage response mechanisms in M. tuberculosis are not well understood, it is clear that for its persistence in the host, DNA repair strategies are vital for this pathogen (Mizrahi \& Andersen, 1998).

The genome sequences of M. tuberculosis (Cole et al., 1998), Mycobacterium leprae (Cole et al., 2001; Smith et al., 1997) and Mycobacterium smegmatis (http://www.tigr.org) have suggested that mismatch repair enzymes are missing in these organisms (Mizrahi \& Andersen, 1998), and the role of RecA has been found to be minimal in mutation prevention (Boshoff et al., 2003; Rand et al., 2003). Thus, among the major DNA repair pathways, the base excision repair (BER) and the nucleotide excision repair (NER) pathways presumably contribute significantly to the maintenance of the genomic integrity in these bacteria. The high $\mathrm{G}+\mathrm{C}$ content $(\sim 65 \mathrm{~mol} \%)$ of the genomes of mycobacteria puts them at a greater risk of cytosine deamination (to uracil), and oxidative damage of guanosine (to 8-oxoG). The pathways that repair uracil and 8-oxoG are initiated by uracil DNA glycosylase (Ung or UDG; Lindahl, 1979; Duncan, 1981; Krokan et al., 1997) and formamidopyrimidine DNA glycosylase (Fpg or MutM, Bailly et al., 1989; Tchou et al., 1991; Graves et al., 1992), respectively, which are also two important BER enzymes in mycobacteria (Venkatesh et al., 2003; Jain et al., 2007). On the other hand, UvrB is a central player in NER (Skorvaga et al., 2002). 
Earlier studies have shown that a $u v r B$-deficient strain of M. tuberculosis (Darwin et al., 2003) is markedly attenuated for survival in mice (Darwin \& Nathan, 2005). However, there appear to have been no studies in which the relative importance of the DNA repair pathways in survival of mycobacteria has been compared in an isogenic strain background. Mutants of $M$. tuberculosis defective in ung or $f p g$ have not been explored. Similarly, mutants of $M$. smegmatis defective in NER have been hitherto unavailable.

In this study, we generated a $u v r B$-deficient strain of $M$. smegmatis, and compared the relative fitness of this strain with those deficient in Ung $\left(u n g^{-}\right)$or Fpg $\left(f p g^{-}\right)$, the two important BER pathway enzymes, under commonly encountered conditions that damage DNA.

\section{METHODS}

Plasmids, media and growth conditions. Plasmids are listed in Table 1, and the details of various strains generated from $M$. smegmatis $\mathrm{mc}^{2} 155$ (Snapper et al., 1990) are listed in Table 2. $M$. smegmatis strains were grown in LB containing $0.2 \%(\mathrm{v} / \mathrm{v})$ Tween 80 (LBT) or Middlebrook 7H9 (Difco) containing $0.2 \%(\mathrm{v} / \mathrm{v})$ glycerol and $0.2 \%$ Tween 80 . For growth on solid surfaces, $1.5 \%$ agar was included in the media. When specified, 7H10 medium (Difco) containing $0.5 \%(\mathrm{v} / \mathrm{v})$ glycerol and $0.05 \%$ Tween 80 was used to obtain isolated colonies from glycerol stocks of various strains. Media were supplemented with hygromycin, gentamicin and kanamycin at 50,5 and $50 \mu \mathrm{g} \mathrm{ml}^{-1}$, respectively, as needed.

Disruption of the uvrB gene in $\boldsymbol{M}$. smegmatis. M. smegmatis uvrB gene (Msm-uvrB, MSMEG_3816; http://www.tigr.org) was identified (Fig. 1a) by its homology to M. tuberculosis uvrB (Rv1633; Cole et al., 1998 ) and the relevant part of it was PCR amplified using primers UvrB-Fp1 (5'-AGCCTGCAGTGGTGTTGCTCGGCGC-3', which anneals $\sim 160$ bp downstream of the start codon in the UvrB ORF) and UvrB-Rp1 (5'-GCCAGCTCGAACTGCAGGTCG-3', which anneals $\sim 70 \mathrm{bp}$ upstream of the stop codon) and DyNAzyme EXT DNA polymerase (Finnzymes). PCR was carried out in a $50 \mu \mathrm{l}$ reaction containing $1.5 \mathrm{U}$ DyNAzyme EXT DNA polymerase
(Finnzymes), $250 \mathrm{ng}$ M. smegmatis SN2 genomic DNA, 20 pmol of each primer, $3.5 \mathrm{mM} \mathrm{MgSO}$, $5 \%$ DMSO, DyNAzyme EXT reaction buffer and $200 \mu \mathrm{M}$ dNTPs. After initial denaturation for $4 \mathrm{~min}$ at $94{ }^{\circ} \mathrm{C}, 30$ cycles of incubations were carried out at $94{ }^{\circ} \mathrm{C}$ for $1 \mathrm{~min}$, $64{ }^{\circ} \mathrm{C}$ for $30 \mathrm{~s}$ and $72{ }^{\circ} \mathrm{C}$ for $2 \mathrm{~min}$, followed by a final extension step at $72{ }^{\circ} \mathrm{C}$ for $10 \mathrm{~min}$. The amplicon $(\sim 1.9 \mathrm{~kb})$ was digested with Pst I and cloned into similarly digested pUC4k (Vieira \& Messing, 1982), resulting in pUC4k-MsmUvrB, which was then digested with $S p h \mathrm{I}$ (internal to Msm-uvrB), blunt-ended with T4 DNA polymerase and ligated to a kanamycin cassette $(\sim 1.3 \mathrm{~kb}$ HincII fragment from pUC4k) to generate pUC4k-Msm-uvrB:: $\mathrm{kan}^{\mathrm{R}}$. A $3.2 \mathrm{~kb}$ BamHI fragment from this construct containing Msm-uvrB:: $k a n^{\mathrm{R}}$ was then mobilized into the BamHI site of pPR27 (Pelicic et al., 1997) to generate pPR-Msm-uvrB::kan ${ }^{\mathrm{R}}$, which was introduced into $M$. smegmatis $\mathrm{mc}^{2} 155$ by electroporation (Hatfull \& Jacobs, 2002) to generate the knockout strain using a protocol described before (Pelicic et al., 1997; Venkatesh et al., 2003).

Genomic blot analysis. Genomic DNAs $(\sim 2.5 \mu \mathrm{g})$ were digested with an excess of restriction enzymes $(20 \mathrm{U})$, separated on a $0.7 \%$ agarose gel using TBE buffer, transferred (Reed \& Mann, 1985) to nylon membrane (Biodyne B, Pall Gelman Laboratory) and subjected to hybridization (Vasanthakrishna et al., 1997) with radiolabelled probe prepared by PCR using $\left[\alpha-{ }^{32} \mathrm{P}\right] \mathrm{dCTP}$ and primers UvrB-Fp2 (5'-CGCACCGGCAAACCCTTCG-3') and UvrB-Rp2 (5'-CGCGAATTCAGTCACGACGAC-3') (Sambrook et al., 1989) using PCR product obtained by the same primers under standard conditions as template.

Generation of the uvrB-complemented strain. DNA oligomers UvrB-Fp3 (5'-CTATAAGCTTCGGGATCGGTATTG-3', which anneals $\sim 244$ bp upstream of the start codon in ORF) and UvrBRP3 (5'-CGCTCGCTGTTTCGGTCACTTCAG-3', which anneals $\sim 15$ bp downstream of the termination codon) were used to PCR amplify Mtu-uvrB (Rv1633) from M. tuberculosis H37Rv genomic DNA (250 ng) using $1 \mathrm{U}$ DyNAzyme EXT (Finnzyme) in a $50 \mu \mathrm{l}$ reaction. The PCR conditions included an initial step of heating at $94{ }^{\circ} \mathrm{C}$ for $4 \mathrm{~min}$ followed by 30 cycles of incubations at $94{ }^{\circ} \mathrm{C}$ for $1 \mathrm{~min}, 47^{\circ} \mathrm{C}$ for $30 \mathrm{~s}$ and $72{ }^{\circ} \mathrm{C}$ for $2 \mathrm{~min} 45 \mathrm{~s}$ and a final extension at $72{ }^{\circ} \mathrm{C}$ for $10 \mathrm{~min}$. The amplicon $(2.2 \mathrm{~kb})$ was digested with HindIII, ethanol precipitated, phosphorylated with polynucleotide kinase, gel purified and cloned between the AgeI (blunt-ended) and HindIII sites of pMV361 $\left(h y g^{\mathrm{R}}\right)($ Stover et al., 1991) to generate pMV-

Table 1. List of plasmids

\begin{tabular}{|c|c|c|}
\hline pUC4k $\left(k^{2} n^{\mathrm{R}}\right)$ & Multicopy plasmid (E. coli) containing a $k^{2} n^{\mathrm{R}}$ cassette & Vieira \& Messing (1982) \\
\hline pUC4k-Msm-UvrB & pUC4k harbouring a truncated ORF of $M$. smegmatis uvrB (MSMEG_3816) & This study \\
\hline pPR27 $\left(\mathrm{Gm}^{\mathrm{R}}\right)$ & $\begin{array}{l}\text { E. coli-mycobacteria shuttle vector containing a temperature-sensitive ori } \\
\text { (pAL5000) for replication in mycobacteria and a } s a c B \text { marker for its } \\
\text { counterselection }\end{array}$ & Pelicic et al. (1997) \\
\hline pMV361 $\left(h y g^{\mathrm{R}}\right)$ & $\begin{array}{l}\text { Vector that replicates in E. coli and contains an att site for integration } \\
\text { into the L5 att site in mycobacteria }\end{array}$ & Stover et al. (1991) \\
\hline pMV-Mtu-uvrB $\left(h y g^{\mathrm{R}}\right)$ & pMV361 harbouring $M$. tuberculosis uvrB (Rv1633) & This study \\
\hline pPRmsUng & pPR27 harbouring M. smegmatis ung & Venkatesh et al. (2003) \\
\hline pMV-ung $\left(h y g^{\mathrm{R}}\right)$ & pMV361 harbouring M. smegmatis ung & This study \\
\hline pTKmx & $\begin{array}{l}\text { Shuttle vector harbouring ColE1 (E. coli) and pAL5000 (mycobacteria) } \\
\text { origins of replication and } \mathrm{kan}^{\mathrm{R}} \text { marker }\end{array}$ & $\begin{array}{l}\text { Kenney \& Churchward } \\
\text { (1996) }\end{array}$ \\
\hline
\end{tabular}


Table 2. M. smegmatis strains

\begin{tabular}{|c|c|c|}
\hline Strain & Relevant details & Reference \\
\hline $\mathrm{mc}^{2} 155$ & High-efficiency transformation strain & Snapper et al. (1990) \\
\hline$u v r B:: k a n^{\mathrm{R}}$ & $\mathrm{mc}^{2} 155$ where $u v r B$ (MSMEG_3816) has been disrupted with kan cassette & This study \\
\hline$f p g:: h y g^{\mathrm{R}}$ & $\mathrm{mc}^{2} 155$ where $f p g$ has been replaced with $h y g$ cassette & Jain et al. (2007) \\
\hline ung:: $\operatorname{kan}^{\mathrm{R}}$ & $\mathrm{mc}^{2} 155$ ung has been disrupted with $k a n$ cassette & Venkatesh et al. (2003) \\
\hline WT & $\begin{array}{l}\text { Designation used in this study for } \mathrm{mc}^{2} 155 \text { harbouring pDK20 }\left(k^{2} n^{\mathrm{R}}\right) \text { at the L5 } \\
\text { att site in the chromosome }\end{array}$ & Venkatesh et al. (2003) \\
\hline$u v r B^{-}$ & $\begin{array}{l}\text { M. smegmatis uvrB:: } \text { kan }^{\mathrm{R}} \text { strain harbouring pMV361 }\left(h y g^{\mathrm{R}}\right) \text { at the L5 att site in the } \\
\text { chromosome }\end{array}$ & This study \\
\hline$u g^{-}$ & $\begin{array}{l}\text { M. smegmatis ung:: } \text { an }^{\mathrm{R}} \text { strain harbouring pMV361 }\left(h y g^{\mathrm{R}}\right) \text { at the L5 att site in the } \\
\text { chromosome }\end{array}$ & This study \\
\hline$f p g^{-}$ & M. smegmatis fpg:: hyg $g^{\mathrm{R}}$ strain harbouring pTKmx $\left(k n^{\mathrm{R}}\right)$. & Jain et al. (2007) \\
\hline$u v r B^{-}(\mathrm{L} 5 a t t:: u v r B)$ & $\begin{array}{l}\text { M. smegmatis } u v r B:: k^{\mathrm{R}}{ }^{\mathrm{R}} \text { strain harbouring pMV-Mtu-uvrB (Rv1633) at the L5 } \\
\text { att site in the chromosome }\end{array}$ & This study \\
\hline ung $^{-}$(L5att:: ung) & $\begin{array}{l}\text { M. smegmatis ung:: } \mathrm{kan}^{\mathrm{R}} \text { strain harbouring pMV-ung at the L5 att site in the } \\
\text { chromosome }\end{array}$ & This study \\
\hline$f p g^{-}(\mathrm{pTK}-\mathrm{Mtu}-f p g)$ & M. smegmatis $f p g:: h y g^{\mathrm{R}}$ strain harbouring pTK-Mtu-fpg & Jain et al. (2007) \\
\hline
\end{tabular}

Mtu-uvrB, which was then introduced into $M$. smegmatis ( uvrB::kan) by electroporation for its ectopic integration into the chromosome at the L5 att site to generate the $u v r B^{-}$(L5att:: uvrB) strain. The vector alone (pMV361, $h y g^{\mathrm{R}}$ ) was also electroporated into the $u v r B:: k a n$ strain to generate the uvrB::kan L5att::pMV361 (referred to as $u v r B^{-}$) strain. The strain designations have been defined in Table 2.

Generation of the ung-complemented strain. The M. smegmatis ung ORF along with $\sim 700$ bp of upstream and 663 bp of downstream sequences was released as $\sim 2.1 \mathrm{~kb}$ fragment from pPRmsUng (Venkatesh et al., 2003) by digestion with NcoI and XbaI, bluntended using Klenow fragment of DNA polymerase I and subcloned into PvuII-digested pMV361 (Stover et al., 1991) to generate pMVMsm-ung $\left(h y g^{\mathrm{R}}\right)$, which was then introduced into M. smegmatis ung:: kan by electroporation to generate M. smegmatis ung::kan (L5att::ung), referred to as $\left[u^{-} g^{-}\right.$(L5att::ung)], containing an ectopic copy of ung at the L5att site (Table 2).

Assay for UV sensitivity. An early-exponential-phase culture $\left(\mathrm{OD}_{595} \sim 0.4\right)$ of $M$. smegmatis was serially diluted $1: 5$ in LBT in a 96-well plate. Samples from the third dilution onwards were spotted on LBT agar plates with a 48-pronged spotter (Sigma) and plates were exposed to UV C in a biosafety cabinet to UV intensities of 0,30 or $60 \mathrm{~J} \mathrm{~m}^{-2}$ (as measured with a dosimeter), then incubated at $37^{\circ} \mathrm{C}$ for 3 days.

Determination of mutation rates. Mutation rates were determined according to David (1970). Briefly, isolated colonies of the various $M$. smegmatis strains were grown to saturation in $7 \mathrm{H} 9$ medium containing $0.2 \%$ glycerol, $0.1 \%$ Tween 80 and $10 \%$ ADC (Difco) along with the appropriate antibiotics for $48 \mathrm{~h}$. Subsequently, for each strain, 12 independent tubes containing $2 \mathrm{ml}$ each of the same medium but without antibiotics were inoculated with $\sim 1500-2000$ bacteria by diluting from the freshly prepared saturated cultures, and grown for 6 days at $37^{\circ} \mathrm{C}$ with vigorous shaking. Absence of spontaneous mutants in the inoculum (used to develop the 6 day cultures) was confirmed by plating an equivalent aliquot of the culture on $7 \mathrm{H} 10$ containing $0.5 \%$ glycerol, $10 \%$ OADC (Difco) and $100 \mu \mathrm{g}$ rifampicin $\mathrm{ml}^{-1}$. At the end of the 6 day growth, small aliquots from cultures were used to determine total viable counts by dilution plating on LBT agar, and the cells from the remainder of the cultures were harvested and plated on $7 \mathrm{H} 10$ containing $0.5 \%$ glycerol, $10 \%$ OADC and $100 \mu \mathrm{g}$ rifampicin $\mathrm{ml}^{-1}$. The plates were incubated for 3-5 days and the colonies appearing on the plates were counted. The mutation rates for each replicate of the strain were determined and mean mutation rates were calculated (David, 1970).

Effect of acidified sodium nitrite. Isolated colonies of M. smegmatis strains were grown in triplicate in $7 \mathrm{H} 9$ medium with appropriate antibiotics to saturation $(55-60 \mathrm{~h})$. The cultures were serially diluted $1: 100$ in LBT (pH 5.5) with $0.5 \%$ (w/v) BSA, supplemented with 0 , $0.5,1.5$ or $2.5 \mathrm{mM}$ freshly prepared sodium nitrite (Merck, India), seeded in the microtitre wells of honeycomb plates and incubated in a Bioscreen $\mathrm{C}$ kinetic growth reader at $37{ }^{\circ} \mathrm{C}$ with constant shaking at maximum amplitude. Growth was monitored by the machine, which measured $\mathrm{OD}_{600}$ at $3 \mathrm{~h}$ intervals for $39 \mathrm{~h}$.

Effect of hydrogen peroxide on bacterial growth. The effect of $\mathrm{H}_{2} \mathrm{O}_{2}$ on growth was determined in a manner similar to that of acidified sodium nitrite except that the saturated cultures of $M$. smegmatis strains were diluted in LBT with $0.5 \%$ BSA containing 0 , $0.5,1.0$ or $1.5 \mathrm{mM} \mathrm{H}_{2} \mathrm{O}_{2}$ (Calbiochem).

Effect of hypoxic stress on bacterial survival. M. smegmatis strains were grown to an $\mathrm{OD}_{600}$ of $0.5-0.6\left(\sim 1.5-2.0 \times 10^{8}\right.$ c.f.u. $\left.\mathrm{ml}^{-1}\right)$ in Dubos medium with 10\% ADC and diluted 1:100 in triplicate in screw-cap flat-bottom culture tubes containing $20 \mathrm{ml}$ of the same medium and $10 \mathrm{ml}$ of air space (headspace ratio 0.5; Dick et al., 1998). The tubes were sealed and the cultures were grown with slow stirring using a multipoint magnetic board at $37^{\circ} \mathrm{C}$ for 10 days. Total viable counts of these cultures were determined by dilution plating on LBT agar. The cultures (from hypoxic conditions) were also diluted $1: 100$ in triplicate in fresh Dubos medium (with ADC) and recovered aerobically under vigorous shaking conditions at $37{ }^{\circ} \mathrm{C}$. Total viable counts of the recovered cultures were determined at 3, 6, 12 and $24 \mathrm{~h}$ by dilution plating and plotted as $\log _{10}$ c.f.u. $\mathrm{ml}^{-1}$.

\section{RESULTS}

\section{uvrB gene disruption in $M$. smegmatis}

The nucleotide sequence of the $M$. smegmatis $u v r B$ gene (MSMEG_3816) was retrieved from the M. smegmatis 
sequence available at the TIGR website by BLAST search using the M. tuberculosis uvrB (Rv1633) sequence as query. The two were found to be highly conserved at both the amino acid level ( $~ 95 \%$ similarity and $~ 92 \%$ identity) and the nucleotide sequence level $(85.3 \%)$. The genomic contexts of $u v r B$ in $M$. tuberculosis and M. smegmatis are shown in Fig. 1(a). The M. smegmatis uvrB knockout strain was generated by insertion of a kanamycin resistance $\left(\mathrm{kan}^{\mathrm{R}}\right)$ cassette $(\sim 1.3 \mathrm{~kb})$ within the ORF of $u v r B$ (Fig. 1b). The disruption of chromosomal $u v r B$ was confirmed by genomic blot analysis. As expected (Fig. 1b), a ScaI/BamHI double digest resulted in detection of a $\sim 2.5 \mathrm{~kb}$ fragment (Fig. 1c, lane 1) from the wild-type and a $\sim 3.8 \mathrm{~kb}$ fragment from the knockout strains (lanes 2 and 3). The NarI digests also showed the expected fragment sizes of $\sim 2.3 \mathrm{~kb}$ for the wild-type (lane 4 ) and $\sim 3.6 \mathrm{~kb}$ for the knockout strain (lanes 5 and 6). These results confirmed the authenticity of the $u v r B$ gene knockout. Assays of Fpg and Ung activity (performed as previously described: Venkatesh et al., 2003; Jain et al., 2007) confirmed that neither of these activities was disrupted in the $u v r B$ deletion mutant (data not shown).

\section{Analysis of the mutation rates}

To investigate the effect of the UvrB deficiency (deficiency of NER) on the mutation rates of the strain and to compare it with those of strains deficient in the BER pathways ( $u n g-$ and $f p g^{-}$) in M. smegmatis, we determined the mutation rates of the bacterial cultures by scoring for appearance of rifampicin-resistant colonies in the various strains. As shown in Table 3, the loss of Fpg or UvrB proteins resulted in a $\sim 2.5$-fold increase in the mutation rates compared to the wild-type strain. On the other hand, under the same conditions, the deficiency of Ung resulted in a $\sim 9$-fold increase in the mutation rate.

\section{Analysis of UV sensitivity}

Earlier studies showed that a $M$. tuberculosis strain deficient in $u v r B$ did not grow following exposure to UV (Darwin \& Nathan, 2005). We compared the sensitivity to UV radiation of $M$. smegmatis strains deficient in DNA repair enzymes. All the strains showed similar growth when not exposed to $\mathrm{UV}$ (Fig. 2, $0 \mathrm{~J} \mathrm{~m}^{-2}$ ). However, the strain deficient in $u v r B$ was highly sensitive to $\mathrm{UV} C$ radiation

(a)

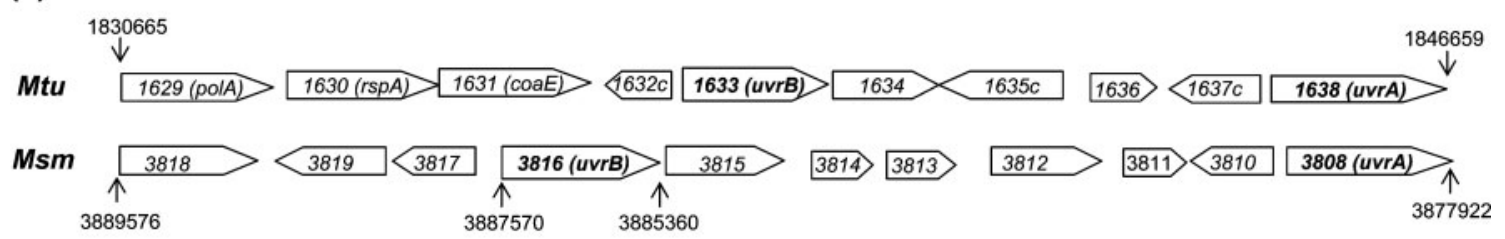

(b)

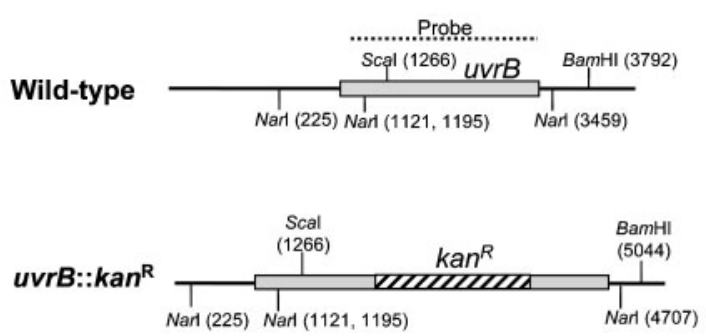

(c)

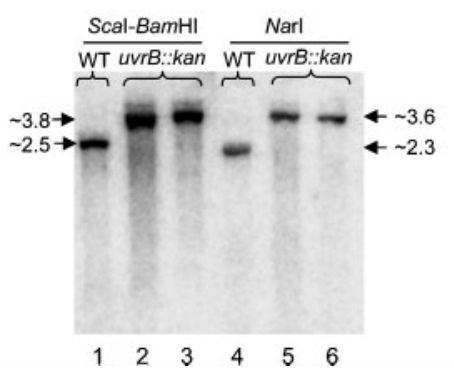

Fig. 1. Generation and characterization of the M. smegmatis uvrB: : kan strain. (a) Schematic representation (not to scale) of the genomic context of uvrB in M. smegmatis (Msm) between positions 3877922 and 3889576 , and comparison with that from the M. tuberculosis (Mtu) genome. Details of various annotated genes in Mtu and Msm genomes are as follows: Rv1629, polA; Rv1630, rspA; Rv1631, coaE; Rv1632c, hypothetical protein; Rv1633, uvrB; Rv1634, possible drug efflux membrane protein; Rv1635c, probable conserved transmembrane protein; Rv1636, iron-regulated conserved hypothetical protein TB15.3; Rv1637c, hypothetical protein; Rv1638, uvrA; MSMEG_3808, uvrA; MSMEG_3810, probable hydrolase (HMM PF00753 family); MSMEG_3811, probable universal protein stress family protein; MSMEG_3812, acyl-CoA thioesterase; MSMEG_3813, NAD-dependent epimerase/dehydratase; MSMEG_3814, tRNA-Cys; MSMEG_3815, possible drug efflux membrane protein; MSMEG_3816, uvrB; MSMEG_3817, conserved hypothetical protein; MSMEG_3818, thermolabile glutaminase; MSMEG_3819, conserved hypothetical protein. (b) Schematic drawing of the wild-type and disrupted (uvrB:: kan) uvrB loci in $M$. smegmatis, showing various restriction endonuclease sites. The location of the uvrB-specific probe prepared in the presence of $\left[\alpha^{-32} \mathrm{P}\right] \mathrm{dCTP}$ by a PCR-based method marked is indicated by the dotted line labelled 'Probe' above the wild-type locus. (c) Genomic blot analysis of $M$. smegmatis strains. Sizes of DNA bands (sizes in kb) are as indicated. 
Table 3. Effect of deficiency in DNA repair enzymes on mutator phenotypes

\begin{tabular}{|lccc|}
\hline Strain & $\begin{array}{c}\mathbf{1 0}^{-\mathbf{9}} \times \text { Total } \\
\text { no. of viable } \\
\text { bacteria plated }\end{array}$ & $\begin{array}{c}\mathbf{1 0}^{\mathbf{1 0}} \times \text { Mutation } \\
\text { rate } \dagger\end{array}$ & $\begin{array}{c}\text { Fold } \\
\text { increase }\end{array}$ \\
\hline WT & $8.9 \pm 0.91$ & 1.83 & 1.0 \\
ung:: kan & $8.2 \pm 0.54$ & 16.9 & 9.2 \\
fpg:: hyg & $7.9 \pm 1.8$ & 4.64 & 2.5 \\
uvrB:: kan & $8.3 \pm 0.517$ & 4.73 & 2.6 \\
\hline
\end{tabular}

${ }^{\star}$ Mean \pm SD of the total viable counts (determined by dilution plating of an aliquot) of bacteria in the 6 day cultures used to plate on rifampicin plates.

$\dagger$ Mutation rates were calculated according to David (1970) using the equation $a=2 \ln 2\left[\left(M_{t} / N_{t}\right)-\left(M_{0} / N_{0}\right)\right] / n$, where $a$ is the mutation rate, $n$ the number of generations, $M_{t}$ the number of Rif $^{\mathrm{R}}$ colonies obtained from the 6 day culture (Methods), $N_{t}$ the number of bacteria in the 6 day culture, $M_{0}$ the number of Rif ${ }^{\mathrm{R}}$ colonies in the starter culture used to make the 6 day culture, and $N_{o}$ the number of bacteria in the starter culture used to make the 6 day culture. The value of $n$ was calculated as $\left(\log N_{t}-\log N_{0}\right) / 0.301$. As the value of $M_{0}$ was zero, the simplified equation $a=2 \ln 2\left(M_{t} / N_{t}\right) / n$ was used to calculate mutation rates. Mutation rates were calculated for all 12 replicates of the 6 day cultures, and the mean mutation rates shown were calculated from 10 replicates, eliminating the two with the highest and the lowest rates.

even at $30 \mathrm{~J} \mathrm{~m}^{-2}$. The other strains showed no visible growth defect even at the higher dose of $60 \mathrm{~J} \mathrm{~m}^{-2}$. Based on earlier studies in other organisms (Czeczot et al., 1991; Scott et al., 1999; Huang et al., 2006), it was not unexpected that the deficiency of Ung and Fpg did not result in any increased sensitivity of $M$. smegmatis to UV C radiation. However, these observations highlight that the NER pathway provides the major means to protect $M$. smegmatis against DNA damage caused by UV radiation. As a control, integration of a single copy of the $u v r B$ gene (from $M$. tuberculosis) at the L5 att site in the knockout strain rescued the phenotype (bottom row in Fig. 2), suggesting that the UV sensitivity of the strain was due to UvrB deficiency and not an indirect consequence of chromosomal alteration at the $u v r B$ locus.

\section{Effect of acidified sodium nitrite on the growth of M. smegmatis strains}

Under acidic conditions, sodium nitrite generates nitrous acid, which decomposes to generate a range of RNI (Stuehr et al., 1989; O'Brien et al., 1994). RNI can cause deamination of various bases in DNA or could react with oxygen to form peroxynitrite, causing oxidative damage to cells. Earlier work (Venkatesh et al., 2003; Darwin \& Nathan, 2005) has shown that mycobacterial strains deficient in Ung or UvrB ( $M$. smegmatis and $M$. tuberculosis, respectively) are susceptible to nitric oxide stress. We compared the effect of nitric oxide on strains of M. smegmatis deficient in Fpg, Ung, and UvrB at initial culture $\mathrm{pH}$ of 5.5. Representative growth curves are presented in Fig. 3. As seen in Fig. 3(a), the medium pH of 5.5 itself had an effect on the growth profile of the strains, and the growth of the strain deficient in NER was the most compromised. While the supplementation of the medium with increasing amounts of sodium nitrite (Fig. 3b-d) resulted in additional compromise in the growth of the NER-deficient strain, the effect of the reagent on the $u n g^{-}$strain was more pronounced (e.g. compare its growth with that of the wild-type strain in panels a and c). The effect of the reagent on the $f p g^{-}$strain was the least pronounced. Thus, the $u n g^{-}$and $u v r B^{-}$but not the $f p g^{-}$ strains, under the conditions used, are sensitive to growth in acidified nitrite. As a control, at the highest concentration of the reagent used, the $u n g^{-}, u v r B^{-}$and $f p g^{-}$strains grew like the wild-type parent when complemented with, respectively, an ectopically inserted copy of $u n g$ or $u v r B$ at the L5 att site in the chromosome, and fpg on a vector, pTK-Mtu-fpg (Fig. 3e). It may be noted that the $\mathrm{pH}$ of the medium changes to neutral during the mid-exponential phase of the culture.
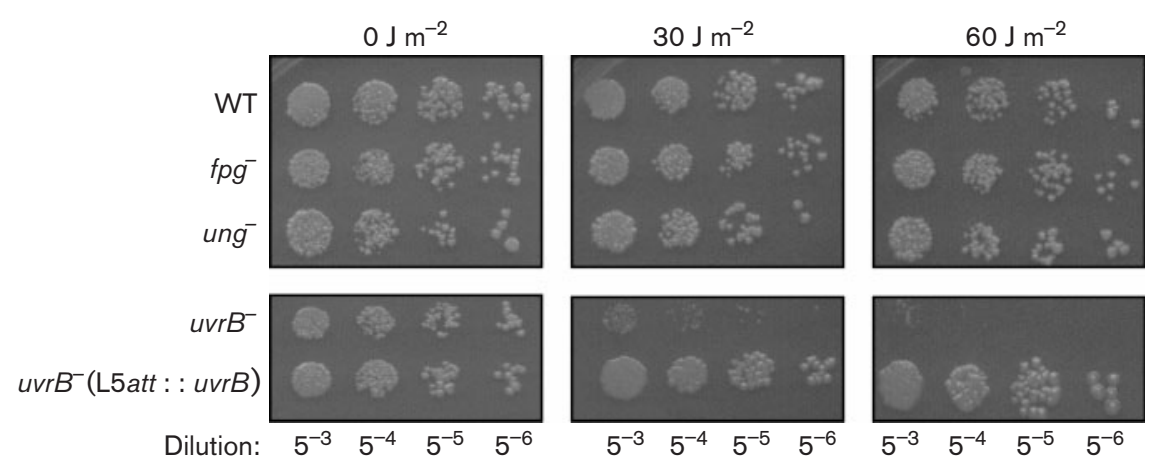

Fig. 2. UV sensitivity assay using $M$. smegmatis strains $\left[\mathrm{WT}, u n g^{-}, f p g^{-}, u v r B^{-}\right.$and $u v r B^{-}(\mathrm{L} 5$ att $\left.:: u v r B)\right]$. Various dilutions (as indicated) of early-exponential-phase cultures were spotted onto LBT agar and either not exposed $\left(0 \mathrm{~J} \mathrm{~m}^{-2}\right)$ or exposed to $30 \mathrm{~J}$ $\mathrm{m}^{-2}$ or $60 \mathrm{~J} \mathrm{~m}^{-2}$ of UV C radiation. The plates were then incubated at $37{ }^{\circ} \mathrm{C}$ for 3 days and imaged. 

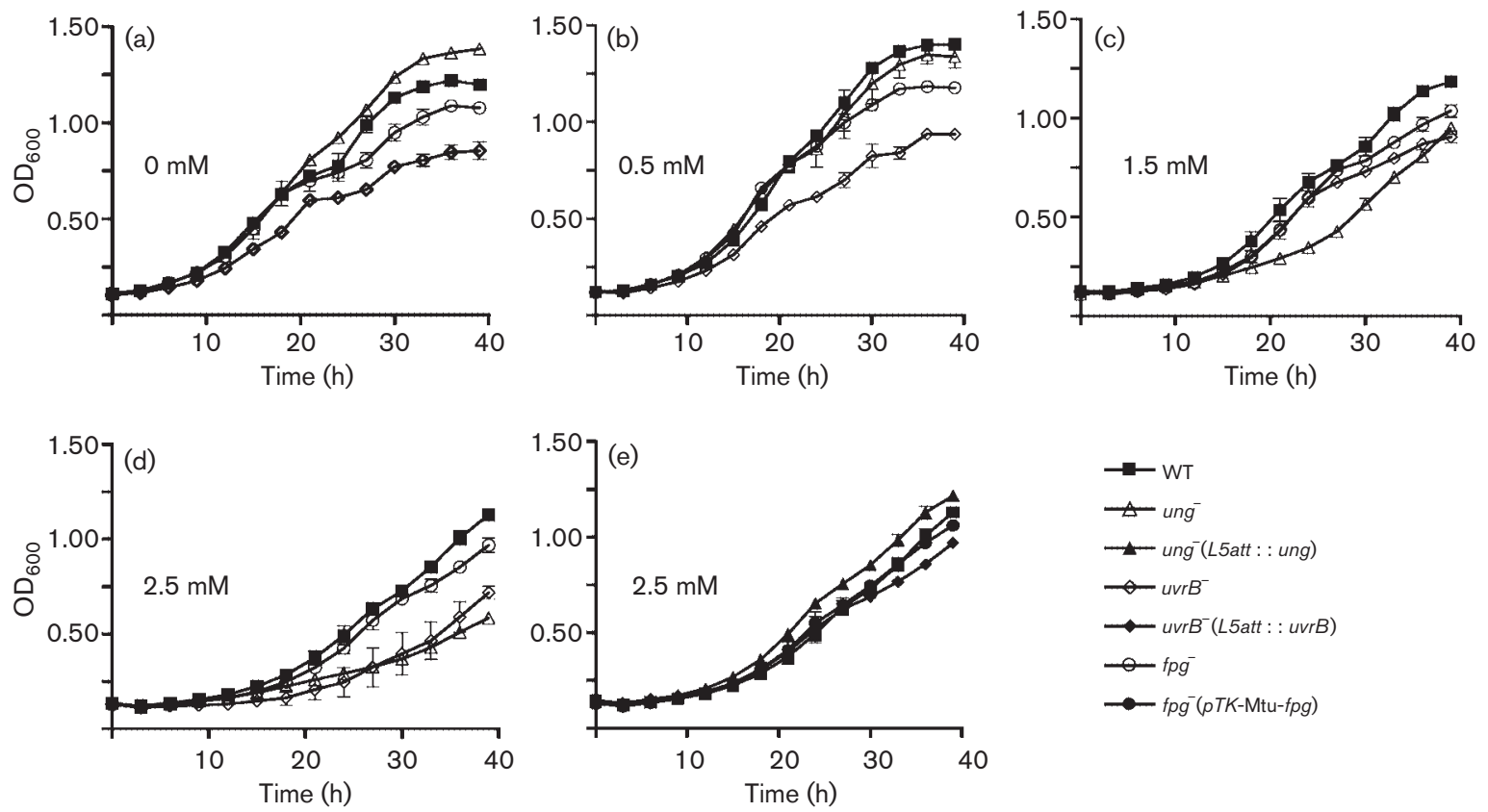

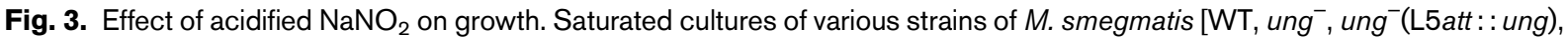
$u v r B^{-}, u v r B^{-}(\mathrm{L} 5 a t t:: u v r B), f p g^{-}$and $f p g^{-}$(pTK-Mtu-fpg)] were diluted 100 -fold in LBT with $0.5 \%$ (w/v) BSA, pH 5.5 containing no $\mathrm{NaNO}_{2}$ (a), $0.5 \mathrm{mM} \mathrm{NaNO}_{2}$ (b), $1.5 \mathrm{mM} \mathrm{NaNO}_{2}$ (c) or $2.5 \mathrm{mM} \mathrm{NaNO}_{2}$ (d, e) and grown at $37{ }^{\circ} \mathrm{C}$ for $39 \mathrm{~h}$ in a Bioscreen $\mathrm{C}$ kinetic growth reader in microtitre plates. Growth curves were prepared from three independent colonies for each strain; means \pm SD are plotted. Analysis of the total viable counts during the exponential and stationary phases of the growth (data not shown) revealed that the $\mathrm{OD}_{600}$ measurements of the various strains gave a true representation of their viability.

\section{Effect of hydrogen peroxide on the growth of M. smegmatis strains}

We previously observed that M. smegmatis deficient in fpg is susceptible to $\mathrm{H}_{2} \mathrm{O}_{2}$ (Jain et al., 2007). Such analyses have not been carried out for the strains deficient in Ung and UvrB. As shown by the representative data in Fig. 4, all the strains showed similar growth kinetics in the absence of $\mathrm{H}_{2} \mathrm{O}_{2}$ (Fig. 4a). Addition of the increasing amounts of $\mathrm{H}_{2} \mathrm{O}_{2}(0.5,1$ and $1.5 \mathrm{mM})$ to the growth medium revealed that the NER-deficient strain was the most sensitive to the reagent, and at $1.5 \mathrm{mM} \mathrm{H}_{2} \mathrm{O}_{2}$ it failed to grow (Fig. 4b-d). At $1 \mathrm{mM} \mathrm{H}_{2} \mathrm{O}_{2}$, a small effect could also be detected for the $f p g^{-}$strain but not the ung ${ }^{-}$strain (Fig. 4c). However, at $1.5 \mathrm{mM} \mathrm{H}_{2} \mathrm{O}_{2}$, growth of both the $f \mathrm{pg}^{-}$and the $u n g^{-}$ strains was also severely impaired. As a control, growth of the complemented strains was similar to that of the wildtype strain even at the highest concentration of the reagent used (Fig. 4e). These observations show that among the strains tested, the $u v r B^{-}$strain is highly susceptible to $\mathrm{H}_{2} \mathrm{O}_{2}$.

\section{Effect of hypoxic stress on growth and survival of the strains}

During latency, pathogenic mycobacteria survive under hypoxia. Wayne has defined in vitro growth conditions to mimic hypoxia using sealed culture tubes with a defined empty space above the medium (Wayne \& Lin, 1982; Wayne \& Hayes, 1996). Earlier reports (Dick et al., 1998; Mayuri et al., 2002) have described adaptation of these growth conditions for M. smegmatis and shown that several physiological changes that the bacterium undergoes during such a growth are common to those encountered by $M$. tuberculosis under the same conditions. Considering that hypoxic conditions are known to induce DNA damage (Moller et al., 2001; Grishko et al., 2001) it was of interest to subject the various DNA-repair-deficient $M$. smegmatis strains to the hypoxic growth model of Wayne. As shown in Fig. 5(a), evaluation of the total viable counts of the various cultures at the end of the growth regimen revealed that in comparison with the WT strain the $u v r B^{-}$strain was the least fit for survival under hypoxia. Although the $u^{-}$strain also showed impaired survival under these conditions, the $\mathrm{fpg}^{-}$strain was unaffected. Importantly, complementation of the $u v r B^{-}$and the $u n g^{-}$strains with the $u v r B$ and $u n g$ genes restored their survival level to the WT level. The complementation of the $f p g^{-}$strain with a plasmid-borne copy of $f p g$ resulted in a slight decrease in total viable counts (in comparison to the $\mathrm{fpg}^{-}$strain). The reasons for this are not clear. Notwithstanding this observation, it is clear that of all the strains, the $u v r B^{-}$ strain is most sensitive to hypoxia as well.

To further analyse the effect of hypoxia on the DNArepair-deficient strains, we subcultured the strains after 

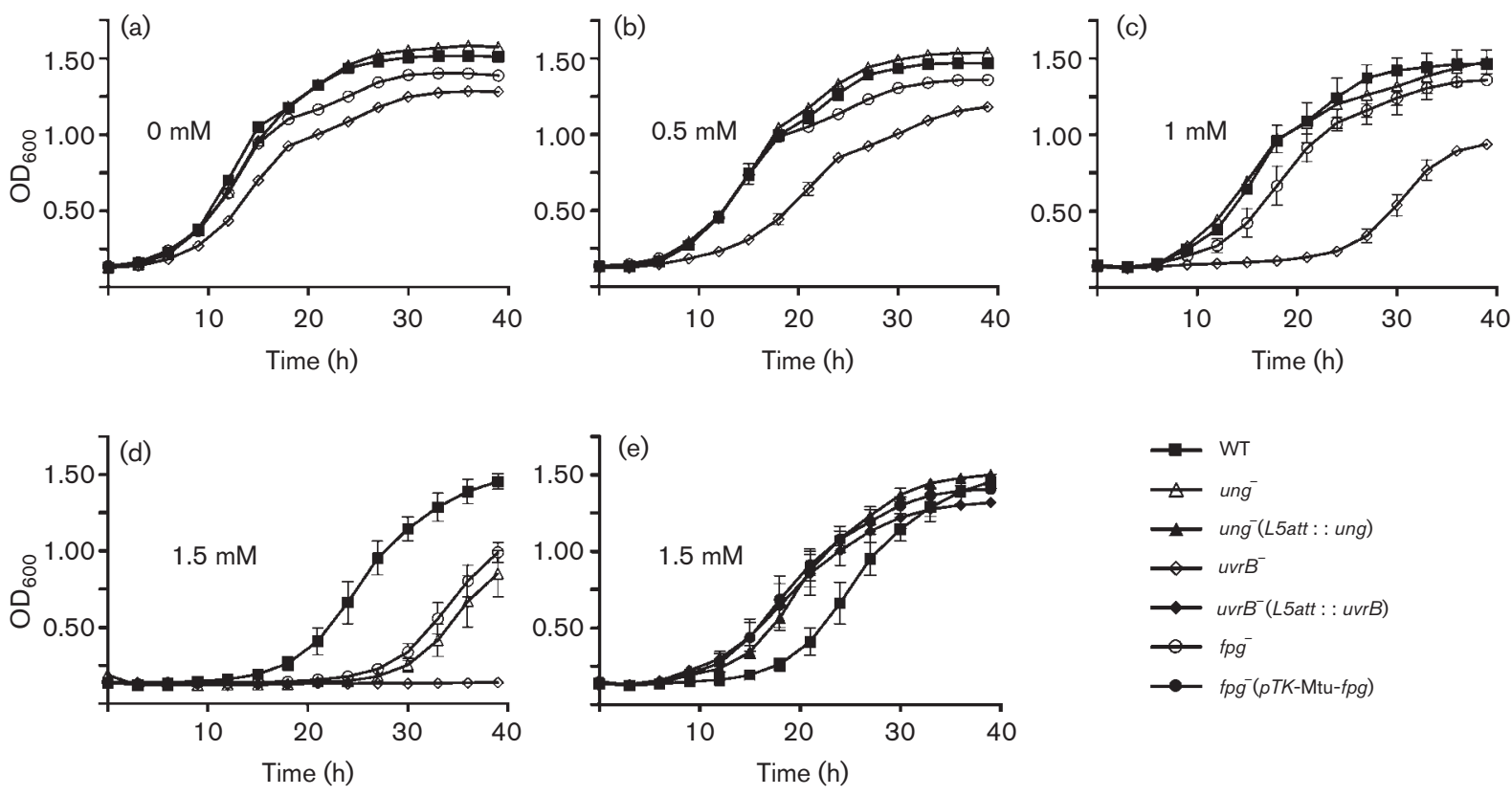

Fig. 4. Effect of $\mathrm{H}_{2} \mathrm{O}_{2}$ on growth. Saturated cultures of various strains of M. smegmatis [WT, ung ${ }^{-}$, ung ${ }^{-}$(L5att: : ung), uvrB ${ }^{-}$, $\mathrm{uvrB}^{-}(\mathrm{L} 5 \mathrm{att}:: \mathrm{uvrB}), \mathrm{fpg}^{-}$and $f p g^{-}$(pTK-Mtu-fpg)] were diluted 100-fold in LBT with $0.5 \%(\mathrm{w} / \mathrm{v})$ BSA. $\mathrm{H}_{2} \mathrm{O}_{2}$ was either not added (a), or added at $0.5 \mathrm{mM}(\mathrm{b}), 1.0 \mathrm{mM}(\mathrm{c})$ or $1.5 \mathrm{mM}(\mathrm{d}, \mathrm{e})$. Cultures were grown at $37{ }^{\circ} \mathrm{C}$ for $39 \mathrm{~h}$ in a Bioscreen $\mathrm{C}$ kinetic growth reader in microtitre plates. Growth curves were done from three independent colonies for each strain; means \pm SD are plotted. As was the case for the experiments in Fig. 3, the $\mathrm{OD}_{600}$ measurements represented true viable counts.

their release from hypoxia and monitored them for their adaptability to growth under normal conditions. Interestingly, while the $u n g^{-}$and the $f p g^{-}$strains recovered well, the $u v r B^{-}$strain was highly compromised even during its recovery phase (Fig. 5b). As expected, all the complemented strains recovered as well as the WT strain.
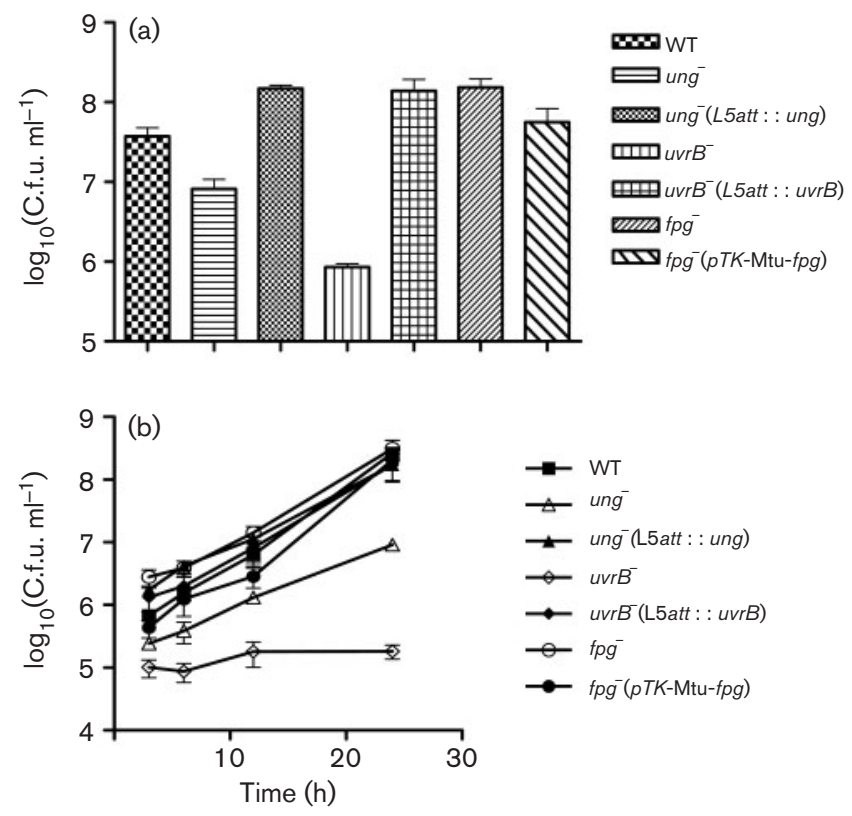

Fig. 5. Effect of hypoxia on survival and recovery of $M$. smegmatis strains using Wayne's model of in vitro growth. Midexponential-phase cultures of various $M$. smegmatis strains (in triplicate) were grown to $\mathrm{OD}_{600} 0.5-0.6$ in Dubos medium with ADC and diluted $1: 100$ in the same medium for growth in sealed screw-cap flat-bottom culture tubes at $37{ }^{\circ} \mathrm{C}$ for 10 days. Viable counts of these cultures were determined by dilution plating on LBT agar. Mean values $( \pm S D$ ) for each strain are shown in (a). The cultures (after release from hypoxia) were also diluted $1: 100$ in triplicate in fresh Dubos medium with ADC and recovered aerobically under vigorously shaken conditions at $37^{\circ} \mathrm{C}$. Viable counts of the recovered cultures were determined at 3 , 6,12 and $24 \mathrm{~h}$ by dilution plating and mean values $( \pm S D)$ are plotted in (b). 


\section{DISCUSSION}

M. tuberculosis exists in the host in either a phase of active multiplication or a phase where it remains latent. Physiological differences between the two phases suggest differential requirements/utilization of the essential biochemical processes during these phases. During the state of latency, while a large number of cellular processes could be downregulated, a compromise in DNA repair processes, essential to maintain the integrity of the genetic blueprint, could prove detrimental to survival. Considering that in the host, M. tuberculosis is exposed to RNI and ROS which are known to damage DNA, a deficiency in the DNA repair capacity of the bacterium would result in accumulation of mutations in its genome and failure of its reactivation. A number of available drugs target mycobacteria in the active multiplication phase. As development of drugs to target the bacilli in the latent phase is a priority, it is crucial to assess the relative importance of different repair pathways in mycobacteria to enable their exploitation as a possible target. To perform such studies, it is desirable that mutations in different repair pathways are available in an isogenic strain background.

As expected for the $\mathrm{G}+\mathrm{C}$-rich genomes of $M$. tuberculosis and M. smegmatis, the Ung- and Fpg-mediated repair pathways represent two of the crucial BER pathways in these bacteria (Venkatesh et al., 2003; Jain et al., 2007). Neither of these repair pathways has been investigated in M. tuberculosis. On the other hand, while the consequences of NER deficiency have been investigated previously (Darwin \& Nathan, 2005) in a transposon insertion mutant of M. tuberculosis (Darwin et al., 2003), its significance had not been reported in M. smegmatis. In this study, we have generated an $u v r B$ knockout strain of $M$. smegmatis to allow a direct comparison of the significance of different DNA repair pathways in mycobacteria.

We previously reported an increase in mutation frequencies of about 8- and 3.8-fold in Ung- and Fpg-deficient strains, respectively (Venkatesh et al., 2003; Jain et al., 2007). As mutation frequency analysis can be influenced by various factors, for a comparative analysis of the mutator phenotypes, in this study we carried out mutation rate analyses (David, 1970). This analysis revealed that Ung, Fpg and UvrB deficiencies resulted in a $~ 9-, 2.6-$ and 2.5fold increase, respectively, in the mutation rates above the WT reference (Table 3). However, compared with Ungand Fpg-deficient strains, the UvrB-deficient strain was more sensitive to exposure to UV, low $\mathrm{pH}, \mathrm{H}_{2} \mathrm{O}_{2}$ and hypoxia (Figs 2, 3, 4 and 5), emphasizing a vital role of NER in mycobacteria. It may be noted that the susceptibility of $M$. smegmatis to $\mathrm{H}_{2} \mathrm{O}_{2}$ is in contrast to the observations made with a uvrB-deficient strain of $M$. tuberculosis (Darwin \& Nathan, 2005). The reasons for this observed difference are unclear, but it may well be that the culture age and the growth conditions play a role in susceptibility to $\mathrm{H}_{2} \mathrm{O}_{2}$ (e.g. the presence of catalase, a component of OADC supplement, in the culture medium of $M$. tuberculosis may neutralize $\mathrm{H}_{2} \mathrm{O}_{2}$ ). Also, while mutational analysis with the NER-deficient strain of M. tuberculosis has not been carried out, our observations on the remaining phenotypes of NER-deficient $M$. smegmatis reinforce the observations made with the $u v r B$ transposon mutant of M. tuberculosis isolated by Darwin et al. (2003) and then extensively characterized by Darwin \& Nathan (2005). Further, while a direct comparison of the effects of the BER and NER such as that carried out in this study is not available, studies in Escherichia coli have shown that NER deficiency resulted in only a marginal increase in mutation frequencies (Pienkowska et al., 1993). Interestingly, Hall (1995) showed that NER deficiency in a tryptophan auxotroph of $E$. coli resulted in a $>100$-fold increase in mutation rates of $\operatorname{trpA46}$ to $\operatorname{trp} A^{+}$under tryptophan starvation. However, under tryptophan-sufficiency conditions the mutation rates were not affected by NER deficiency.

It has also been shown that NER plays a major role in repair of 8-oxoG, cyclo-dA and cyclo-dG (Scott et al., 1999; Kuraoka et al., 2000). In fact, overlapping functions of Fpg and NER have also been suggested by other studies (Kow et al., 1990; Asad et al., 2000). Deamination of guanine to xanthine can also result in depurination to form abasic sites in DNA (Tamir et al., 1996), which could be substrates for NER (Lin \& Sancar, 1989). These observations support our findings on the sensitivity of NER-deficient bacteria to $\mathrm{H}_{2} \mathrm{O}_{2}$.

It is significant that $u v r A$ and $u v r B$ are induced in mycobacteria upon treatment with DNA-damaging agents like mitomycin $\mathrm{C}$ as well as upon infecting human macrophages (Rand et al., 2003; Graham \& Clark-Curtiss, 1999). Thus, NER seems to be central to DNA repair mechanisms in mycobacteria. Taken together, these and earlier observations (Darwin \& Nathan, 2005) show that mycobacteria deficient in NER could be a good candidate for development of attenuated strains, and development of inhibitors against NER proteins may allow an efficient method of killing mycobacteria.

\section{ACKNOWLEDGEMENTS}

We thank Dr R. Manjunath (Department of Biochemistry, Indian Institute of Science, Bangalore) and our laboratory colleagues for their suggestions on the manuscript. This work was supported by grants from the Department of Biotechnology and the Council of Scientific and Industrial Research (CSIR), New Delhi. P. K. and K. K. were supported by senior research fellowships of CSIR, New Delhi.

\section{REFERENCES}

Asad, L. M. B. O., Medeiros, D. C., Felzenszwalb, I., Leitão, A. C. \& Asad, N. R. (2000). Participation of stress-inducible systems and enzymes involved in BER and NER in the protection of Escherichia coli against cumene hydroperoxide. Mutat Res 461, 31-40. 
Bailly, V., Verly, W. G., O’Connor, T. \& Laval, J. (1989). Mechanisms of DNA strand nicking at apurinic/apyrimidinic sites by Escherichia coli [formamidopyrimidine]DNA glycosylase. Biochem J 262, 581-589.

Boshoff, H. I., Reed, M. B., Barry, C. E., III \& Mizrahi, V. (2003). DnaE2 polymerase contributes to in vivo survival and the emergence of drug resistance in Mycobacterium tuberculosis. Cell 113, 183-193.

Cole, S. T., Brosch, R., Parkhill, J., Garnier, T., Churcher, C., Harris, D., Gordon, S. V., Eiglmeier, K., Gas, S. \& other authors (1998). Deciphering the biology of Mycobacterium tuberculosis from the complete genome sequence. Nature 393, 537-544.

Cole, S. T., Eiglmeier, K., Parkhill, J., James, K. D., Thomson, N. R., Wheeler, P. R., Honoré, N., Garnier, T., Churcher, C. \& other authors (2001). Massive gene decay in the leprosy bacillus. Nature 409, 1007-1011.

Cooke, M. S., Evans, M. D., Dizdaroglu, M. \& Lunec, J. (2003). Oxidative DNA damage: mechanisms, mutations and disease. FASEB J 17, 1195-1214.

Czeczot, H., Tudek, B., Lambert, B., Laval, J. \& Boiteux, S. (1991). Escherichia coli Fpg protein and UvrABC endonuclease repair DNA damage induced by methylene blue plus visible light in vivo and in vitro. J Bacteriol 173, 3419-3424.

Darwin, K. H. \& Nathan, C. F. (2005). Role of nucleotide excision repair in virulence of Mycobacterium tuberculosis. Infect Immun 73, $4581-4587$.

Darwin, K. H., Ehrt, S., Gutierrez-Ramos, J. C., Weich, N. \& Nathan, C. F. (2003). The proteasome of Mycobacterium tuberculosis is required for resistance to nitric oxide. Science 302, 1963-1966.

David, H. L. (1970). Probability distribution of drug-resistant mutants in unselected populations of Mycobacterium tuberculosis. Appl Microbiol 20, 810-814.

Dick, T., Lee, B. H. \& Oei, B. M. (1998). Oxygen depletion induced dormancy in Mycobacterium smegmatis. FEMS Microbiol Lett 163, 159-164.

Duncan, B. K. (1981). DNA glycosylases. In The Enzymes, pp. 565586. Edited by P. Boyer. Orlando: Academic Press.

Graham, J. E. \& Clark-Curtiss, J. E. (1999). Identification of Mycobacterium tuberculosis RNAs synthesized in response to phagocytosis by human macrophages by selective capture of transcribed sequences (SCOTS). Proc Natl Acad Sci U S A 96, 11554-11559.

Graves, R. J., Felzenszwalb, I., Laval, J. \& O'Connor, T. R. (1992). Excision of 5'-terminal deoxyribose phosphate from damaged DNA is catalyzed by the Fpg protein of Escherichia coli. J Biol Chem 267, 14429-14435.

Grishko, V., Solomon, M., Breit, J. F., Killilea, D. W., Ledoux, S. P., Wilson, G. L. \& Gillespie, M. N. (2001). Hypoxia promotes oxidative base modifications in the pulmonary artery endothelial cell VEGF gene. FASEB J 15, 1267-1269.

Hall, B. G. (1995). Genetics of selection induced mutations. I. uvrA, $u v r B, u v r C$, and $u v r D$ are selection induced specific mutator loci. J Mol Evol 40, 86-93.

Hartman, P. E., Ames, B. N., Roth, J. R., Barnes, W. M. \& Levin, D. E. (1986). Target sequences for mutagenesis in Salmonella histidinerequiring mutants. Environ Mutagen 8, 631-641.

Hatfull, G. F. \& Jacobs, W. B. (2002). Molecular Genetics of Mycobacteria. Washington, DC: American Society for Microbiology.

Huang, S., Kang, J. \& Blaser, M. J. (2006). Antimutator role of the DNA glycosylase mutY gene in Helicobacter pylori. J Bacteriol 188, 6224-6234.

Jain, R., Kumar, P. \& Varshney, U. (2007). A distinct role of formamidopyrimidine DNA glycosylase (MutM) in down-regulation of accumulation of $\mathrm{G}, \mathrm{C}$ mutations and protection against oxidative stress in mycobacteria. DNA Repair (Amst) 6, 1774-1785.
Kenney, T. J. \& Churchward, G. (1996). Genetic analysis of the Mycobacterium smegmatis rpsL promoter. J Bacteriol 178, 3564-3571.

Kow, Y. W., Wallace, S. S. \& Houten, B. V. (1990). UvrABC nuclease complex repairs thymine glycol, an oxidative DNA base damage. Mutat Res 235, 147-156.

Krokan, H. E., Standal, R. \& Slupphaug, G. (1997). DNA glycosylases in the base excision repair of DNA. Biochem J 325, 1-16.

Kuraoka, I., Bender, C., Romieu, A., Cadet, J., Wood, R. D. \& Lindahl, T. (2000). Removal of oxygen free-radical-induced $5^{\prime}, 8$-purine cyclodeoxynucleosides from DNA by the nucleotide excision-repair pathway in human cells. Proc Natl Acad Sci U S A 97, 3832-3837.

Lancaster, J. R., Jr (1997). A tutorial on the diffusibility and reactivity of free nitric oxide. Nitric Oxide 1, 18-30.

Lin, J. J. \& Sancar, A. (1989). A new mechanism for repairing oxidative damage to DNA: (A)BC excinuclease removes AP sites and thymine glycols from DNA? Biochemistry 28, 7979-7984.

Lindahl, T. (1979). DNA glycosylases, endonucleases for apurinic/ apyrimidinic sites, and base excision-repair. Prog Nucleic Acid Res Mol Biol 22, 135-192.

Manganelli, R., Provvedi, R., Rodrigue, S., Beaucher, J., Gaudreau, L. \& Smith, I. (2004). Sigma factors and global gene regulation in Mycobacterium tuberculosis. J Bacteriol 186, 895-902.

Mayuri, Bagchi, G, Das, T. K. \& Tyagi, J. S. (2002). Molecular analysis of the dormancy response in Mycobacterium smegmatis: expression analysis of genes encoding the DevR-DevS two-component system, Rv3134c and chaperon $\alpha$-crystallin homologues. FEMS Microbiol Lett 211, 231-237.

Mizrahi, V. \& Andersen, S. J. (1998). DNA repair in Mycobacterium tuberculosis. What have we learnt from the genome sequence? $\mathrm{Mol}$ Microbiol 29, 1331-1339.

Moller, P., Loft, S., Lundby, C. \& Olsen, N. V. (2001). Acute hypoxia and hypoxic exercise induce DNA strand breaks and oxidative DNA damage in humans. FASEB J 15, 1181-1186.

O’Brien, L., Carmichael, J., Lowrie, D. B. \& Andrew, P. W. (1994). Strains of Mycobacterium tuberculosis differ in susceptibility to reactive nitrogen intermediates in vitro. Infect Immun 62, 5187-5190.

Pelicic, V., Jackson, M., Reyrat, J. M., Jacobs, W. R., Jr, Gicquel, B. \& Guilhot, C. (1997). Efficient allelic exchange and transposon mutagenesis in Mycobacterium tuberculosis. Proc Natl Acad Sci U S A 94, 10955-10960.

Pienkowska, M., Glickman, B. W., Ferreira, A., Anderson, M. \& Zielenska, M. (1993). Large scale mutational analysis of EMS induced mutation in the lacI gene of Escherichia coli. Mutat Res 288, 123-131.

Rand, L., Hinds, J., Springer, B., Sander, P., Buxton, R. S. \& Davis, E. O. (2003). The majority of inducible DNA repair genes in Mycobacterium tuberculosis are induced independently of RecA. Mol Microbiol 50, 1031-1042.

Reed, K. C. \& Mann, D. A. (1985). Rapid transfer of DNA from agarose gels to nylon membranes. Nucleic Acids Res 13, 7207-7221.

Sambrook, J., Fritsch, E. F. \& Maniatis, T. (1989). Molecular Cloning: a Laboratory Manual, 2nd edn. Cold Spring Harbor, NY: Cold Spring Harbor Laboratory.

Scott, A. D., Neishabury, M., Jones, D. H., Reed, S. H., Boiteux, S. \& Waters, R. (1999). Spontaneous mutation, oxidative DNA damage, and the roles of base and nucleotide excision repair in the yeast Saccharomyces cerevisiae. Yeast 15, 205-218.

Shapiro, R., Dubelman, S., Feinberg, A. M., Crain, P. F. \& McCloskey, J. A. (1977). Isolation and identification of cross-linked nucleosides from nitrous acid treated deoxyribonucleic acid. J Am Chem Soc 99, 302-303. 
Skorvaga, M., Theis, K., Mandavilli, B. S., Kisker, C. \& Van Houten, B. (2002). The beta-hairpin motif of UvrB is essential for DNA binding, damage processing, and UvrC-mediated incisions. J Biol Chem 277, 1553-1559.

Smith, D. R., Richterich, P., Rubenfield, M., Rice, P. W., Butler, C., Lee, H. M., Kirst, S., Gundersen, K., Abendschan, K. \& other authors (1997). Multiplex sequencing of $1.5 \mathrm{Mb}$ of the Mycobacterium leprae genome. Genome Res 7, 802-819.

Snapper, S. B., Melton, R. E., Mustafa, S., Kieser, T. \& Jacobs, W. R., Jr (1990). Isolation and characterization of efficient plasmid transformation mutants of Mycobacterium smegmatis. Mol Microbiol 4, 1911-1919.

Stover, C. K., de la Cruz, V. F., Fuerst, T. R., Burlein, J. E., Benson, L. A., Bennett, L. T., Bansal, G. P., Young, J. F., Lee, M. H. \& other authors (1991). New use of BCG for recombinant vaccines. Nature 351, 456-460.

Stuehr, D. J., Gross, S. S., Sakuma, I., Levi, R. \& Nathan, C. F. (1989). Activated murine macrophages secrete a metabolite of arginine with the bioactivity of endothelium-derived relaxing factor and the chemical reactivity of nitric oxide. J Exp Med 169, 1011-1020.

Tamir, S., Burney, S. \& Tannenbaum, S. R. (1996). DNA damage by nitric oxide. Chem Res Toxicol 9, 821-827.

Tchou, J., Kasai, H., Shibutani, S., Chung, M. H., Laval, J., Grollman, A. P. \& Nishimura, S. (1991). 8-Oxoguanine (8-hydroxyguanine) DNA glycosylase and its substrate specificity. Proc Natl Acad Sci U S A 88, 4690-4694.
Vasanthakrishna, M., Kumar, N. V. \& Varshney, U. (1997). Characterization of the initiator tRNA gene locus and identification of a strong promoter from Mycobacterium tuberculosis. Microbiology 143, 3591-3598.

Venkatesh, J., Kumar, P., Krishna, P. S., Manjunath, R. \& Varshney, U. (2003). Importance of uracil DNA glycosylase in Pseudomonas aeruginosa and Mycobacterium smegmatis, G+C-rich bacteria, in mutation prevention, tolerance to acidified nitrite, and endurance in mouse macrophages. J Biol Chem 278, 24350-24358.

Vieira, J. \& Messing, J. (1982). The pUC plasmids, an M13 mp-7 derived system for insertion mutagenesis and sequencing with universal primers. Gene 19, 259-268.

Wayne, L. G. \& Hayes, L. G. (1996). An in vitro model for sequential study of shiftdown of Mycobacterium tuberculosis through two stages of nonreplicative persistence. Infect Immun 64, 2062-2069.

Wayne, L. G. \& Lin, K.-Y. (1982). Glyoxylate metabolism and adaptation of Mycobacterium tuberculosis to survival under anaerobic conditions. Infect Immun 37, 1042-1049.

Wink, D. A., Kasprzak, K. S., Maragos, C. M., Elespuru, R. K., Misra, M., Dunams, T. M., Cebula, T. A., Koch, W. H., Andrews, A. W. \& other authors (1991). DNA deaminating ability and genotoxicity of nitric oxide and its progenitors. Science 254, 1001-1003.

Edited by: G. R. Stewart 